\title{
INFLATION, GOVERNMENT TRANSFERS, AND OPTIMAL CENTRAL BANK INDEPENDENCE
}

\author{
by
}

Diana N. Weymark

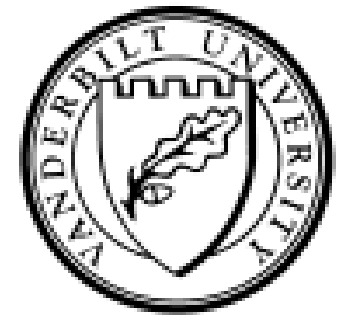

Working Paper No. 05-W02

January 2005

\section{DEPARTMENT OF ECONOMICS \\ VANDERBILT UNIVERSITY \\ NASHVILLE, TN 37235}

www.vanderbilt.edu/econ 


\title{
Inflation, Government Transfers, and Optimal Central Bank Independence*
}

\author{
by \\ Diana N. Weymark \\ Department of Economics, \\ Vanderbilt University, \\ Nashville, TN 37235 \\ diana.weymark@vanderbilt.edu
}

January 2005

* I have benefited from discussions with Andrew Hughes Hallett and Peter Howitt. I am also grateful to two anonymous referees for their constructive comments on an earlier version of this article. 


\section{Abstract \\ Inflation, Government Transfers, and Optimal Central Bank Independence}

The problem of monetary policy delegation is formulated as a two-stage noncooperative game between the government and the central bank. The solution to this policy game determines the optimal combination of central bank conservatism and independence. The results show that the optimal institutional design always requires some degree of central bank independence and that there is substitutability between central bank independence and conservatism. The results also show that partial central bank independence can be optimal and that there are circumstances under which it is optimal for the government to appoint a liberal central banker.

Journal of Economic Literature Classification No.: E52.

Keywords: central bank conservatism, central bank independence, inflation bias, liberal central banker. 


\section{Introduction}

The problem of inflationary bias, which was first identified by Kydland and Prescott (1977), has at its root a time inconsistency problem that arises because there is a potential for surprise inflation to generate output increases. Inflationary bias occurs when rational agents, recognizing that the government may be tempted to use surprise inflation to expand output, demand higher wages, thereby neutralizing the impact of the price increase on output.

Rogoff (1985) showed that inflationary bias can be reduced by delegating monetary policy to an independent central banker who assigns a higher relative weight to inflation control than society does. ${ }^{1}$ In his analysis, Rogoff implicitly assumed that the central bank was free to use its policy instrument as it wished (instrument independence) and also free of government influence over its policy objectives (goal independence). In practice, however, countries differ widely in the degree of independence they confer upon their central banks and even the most independent central banks, who typically do have complete instrument independence, are not entirely free of government oversight.

There now exists an extensive empirical literature that provides convincing evidence of a negative correlation between central bank independence and inflation in industrial countries. However, this inverse relationship appears not to be causal. This suggests that there are underlying country-specific factors which jointly determine inflation performance and the preferred degree of central bank independence. In the

\footnotetext{
${ }^{1} \mathrm{An}$ alternative solution, which focuses on designing binding contracts that alter the incentives of the central bank in such a way as to achieve society's preferred outcome, was introduced by Persson and Tabellini (1993) and Walsh (1995), and has been extended by Beetsma and Jensen (1998), Jonsson (1997), Lockwood (1997), Muscatelli (1998), Schaling, Hoeberichts, and Eijffinger (1998), and Svensson (1997), among others. Walsh (1998) shows that a contract that imposes a quadratic penalty on the central bank for missing its inflation target is equivalent to appointing Rogoff's conservative central banker. Herrendorf and Lockwood (1997) show that both a linear inflation contract and a conservative central banker are needed to mitigate a stochastic inflationary bias.
} 
empirical literature, central bank independence generally refers to the central bank's ability to make decisions independently of the government. It is this type of independence that the various indices of central bank independence attempt to measure. Relatively few theoretical studies of monetary policy delegation have focused on the determinants of the optimal degree of central bank independence in this sense; in most cases, central bank independence has been identified with central bank conservatism. ${ }^{2}$ This is somewhat unsatisfactory because the failure to distinguish between central bank conservatism and independence is formally equivalent to assuming that the central bank's ability to make independent decisions is complete, and exogenously determined.

The need to distinguish formally between the concepts of central bank independence and conservatism has also been recognized by Eijffinger and Hoeberichts (1998). Using a game-theoretic framework, Eijffinger and Hoeberichts show that there exists a continuum of combinations of central bank independence and conservatism which may be optimal. They are also able to demonstrate that the optimal combinations of conservatism and independence are functions of the behavioral and structural parameters in their model. However, although Eijffinger and Hoeberichts model the game between the monetary authority and private agents (wage-setters), they do not allow for strategic interaction between the monetary authority and the government. This has two consequences. First, although the upper and lower bounds of the optimal range for combinations of independence and conservatism can be derived, none of the intermediate optimal combinations can be identified. Second, the analysis cannot overcome McCallum's (1995) criticism that delegating monetary policy to the central bank merely relocates the time inconsistency problem rather than solving it.

The issue of monetary policy delegation has typically been studied using models that do not allow for strategic interaction between the central bank and the government. Alesina and Tabellini (1987), Lohmann (1992) and Debelle and Fisher (1994)

\footnotetext{
${ }^{2}$ See, for example, Cukierman (1994), Eijffinger and Schaling (1995), and Debelle and Fischer (1994).
} 
are a notable exceptions. Neither Alesina and Tabellini nor Lohmann are directly concerned with the determinants of central bank independence. In both studies, the degree of central bank independence is treated as exogenous, and neither study considers the potential benefits of less than full independence. Debelle and Fisher also treat the degree of independence as exogenous, but they recognize that different degrees of independence may be more or less desirable from society's point of view. ${ }^{3}$

In this article, I use a model of strategic interaction between the government and the central bank to explore the relationship between central bank independence and conservatism. In order to do so, I distinguish between central bank independence and conservatism and also between the objectives of a fully independent central bank and those of the government. Central bank independence is defined as the ability of the central bank to set its own policy goals. The objectives of the central bank center only around inflation stabilization and output performance, whereas the government has wider ranging concerns which include, in addition to inflation and output performance, the ability to make transfer payments and the desire to avoid using tax increases to finance these payments.

The interaction between the government and the central bank takes the form of a two-stage non-cooperative game. In the first stage of the game, the government appoints a central banker and chooses how much independence to grant the central bank. In the second stage, the central bank and the government move simultaneously; the government sets taxes and the central bank sets the size of the money supply. The government is subject to a budget constraint and understands that the characteristics of the monetary institution established in period one will have a significant impact on monetary policy and therefore on the government's ability to make transfer payments in period two. Because the degree to which monetary policy is delegated to the central bank is a Nash equilibrium, neither policy authority has an incentive to deviate

\footnotetext{
${ }^{3}$ Debelle and Fischer (1994) explore the implications of interpreting independence in terms of the degree to which the central bank must accommodate the government's actions by comparing the outcomes of alternative Stackelberg games.
} 
from the solution to the delegation game. Insofar as the game I describe mitigates inflationay bias, it overcomes McCallum's criticism and demonstrates that monetary delegation can be viewed as a solution to the inflationary bias problem.

The rest of this article is organized as follows. The economic model is introduced in Section 2 and the objectives of the government and the central bank are specified and discussed in Section 3. The policy game between the government and the central bank is described and solved in Section 4. In Section 5, the solutions to the game are used to characterize the determinants of optimal central bank conservatism and independence. The relationship between central bank independence and inflation performance is analyzed in Section 6. Concluding comments may be found in Section 7.

\section{The Economic Model}

In this economy there are three distinct groups of agents whose actions jointly determine economic performance. The first group is composed of private economic agents. Private agents are assumed to be rational and fall into one of two economic groups, rich or poor. In this model, private agents influence economic performance through their expectations about inflation. The second group of players is collectively referred to as the government. The government is the fiscal authority in the economy and has at its disposal two policy instruments, discretionary taxes and transfer payments. The third and final player in the economy is the central bank. The central bank, as the monetary authority in the economy, has the money supply as its instrument. ${ }^{4}$ It is assumed that the government, the central bank, and private agents all share the same information about the economy in which they operate. The basic structure of the economy is described by the following three equations.

$$
\begin{gathered}
\pi_{t}=\pi_{t}^{e}+\alpha y_{t}+u_{t} \\
y_{t}=\beta\left(m_{t}-\pi_{t}\right)+\epsilon_{t}, \quad 0<\beta<1
\end{gathered}
$$

\footnotetext{
${ }^{4}$ In assuming that the money supply is the central bank's instrument I am assuming, from the outset, that the central bank has full instrument independence
} 


$$
\begin{gathered}
\tau_{t}^{r}=m_{t}+\tau_{t} \\
\tau_{t}=\tau b y_{t}+\tau_{t}^{x}
\end{gathered}
$$

where $\pi_{t}$ is the inflation rate in period $t, y_{t}$ is short-run output growth in period $t, m_{t}$ is nominal money supply growth in period $t, \tau_{t}^{r}$ denotes the growth in transfer payments in period $t, \tau_{t}$ is the overall growth in the government's tax revenues, $\tau_{t}^{x}$ is the growth in discretionary tax revenues, and $\pi_{t}^{e}$ denotes the rate of inflation that rational agents expect will prevail in period $t$, conditional on the information available at the time expectations are formed. ${ }^{5}$ The variables $u_{t}$ and $\epsilon_{t}$ are random disturbances which are assumed to be independently distributed with zero mean and constant variance. The coefficients $\alpha, \beta, \tau$, and $b$ are positive by assumption. ${ }^{6}$

According to (1), inflation is increasing in the rate of inflation predicted by private agents and in output growth. Equation (2) indicates that output is positively related to growth in the real money supply. ${ }^{7}$ The microfoundations of the aggregate supply equation (1), originally derived by Lucas $(1972,1973)$, are well-known. McCallum (1989) shows that aggregate demand equations like (2) can be derived from a standard, multiperiod utility-maximization problem.

Equation (3) characterizes the government's budget constraint. In each period, the government must finance its expenditures by selling government bonds to the central bank or by levying taxes. In $(3), b$ is the proportion of a change in pre-tax income (output) that goes to the wealthy and $\tau$ is the the income-tax rate. Government

\footnotetext{
${ }^{5}$ All growth rates are defined as changes in the levels of the relevant variables expressed as a proportion of the previous period's output. For example, $m_{t}=\left(M_{t}-M_{t-1}\right) / Y_{t-1}$, where M and Y represent money supply and output levels, respectively.

${ }^{6}$ Hughes Hallett and Weymark (2002) use Taylor's (1993) empirical results to calculate short-run impact multipliers and obtain $\beta$ estimates of $0.50,0.53,0.43$, and 0.13 for France, Germany, Italy, and the United Kingdom, respectively.

${ }^{7}$ Note that the model is expressed in terms of growth rates purely for analytical convenience. Output growth $y_{t}$ in this model is simply the percentage change in output in a given period and should not be confused with long-run rates of growth which are generally not thought to be affected by monetary policy.
} 
expenditures, which may take the form of public goods provision or direct income transfers, are represented by $\tau_{t}^{r}$. $^{8}$

The economic structure I have described contains several special features that require further clarification. First, I have not allowed government expenditures to have a direct impact on output. This reflects the assumption that Ricardian equivalence holds. The broader implication of this assumption is that the government can influence output and inflation performance only by its choice of central bank design.

Second, the government obtains tax revenues from discretionary and non-discretionary sources. I do not allow the government to increase its tax revenues by changing the income tax rate $(\tau)$. Period by period changes in income tax rates are politically very difficult to implement, and it is for this reason that I exclude changes in the tax rate from the government's instrument set. On the other hand, it is quite common for governments to alleviate budgetary difficulties by imposing new taxes when, in their view, the benefits outweigh the political costs. I have therefore included the discretionary $\operatorname{tax} \tau_{t}^{x}$ as a potential source of government revenue.

\section{Government and Central Bank Objectives}

In this article, I allow for the possibility that the government and a fully independent central bank may differ in their objectives in some significant way. In particular, I assume that the government is concerned about inflation stabilization, output growth, making transfer payments, and a potential economic and/or political penalty associated with tax increases. The central bank is concerned only with the first two of

\footnotetext{
${ }^{8}$ The budget constraint is derived as follows. The purchase of government bonds by the central bank in period $t$ generates an increase in the money supply of $M_{t}-M_{t-1}$. The government budget in any period $t$ can be expressed as $T_{t}^{r}=\Delta M_{t}+T_{t}$, where $\Delta M_{t}=M_{t}-M_{t-1}$, and upper-case variables are the levels associated with their lower-case counterparts. Then $\tau_{t}^{r}=m_{t}-m_{t-1}^{\prime}+\tau_{t}$ where $\tau_{t}^{r}=\Delta T_{t}^{r} / Y_{t-1}, m_{t}=\Delta M_{t} / Y_{t-1}, m_{t-1}^{\prime}=\Delta M_{t-1} / Y_{t-1}$, and $\tau_{t}=\Delta T_{t} / Y_{t-1}$. The constraint (3) is obtained by making the simplifying assumption $m_{t-1}^{\prime}=0$.
} 
these objectives. ${ }^{9}$ Formally, the government's loss function is given by

$$
L_{t}^{g}=\frac{1}{2}\left(\pi_{t}-\hat{\pi}\right)^{2}-\lambda_{1}^{g} y_{t}+\frac{\lambda_{2}^{g}}{2}\left[(b-\theta) y_{t}-\tau_{t}^{r}\right]^{2}+\lambda_{3}^{g} \tau_{t}
$$

where $\hat{\pi}$ is the government's inflation target, $\lambda_{1}^{g}$ is the relative weight that the government assigns to output growth, and $\lambda_{2}^{g}$ is the relative weight assigned to income redistribution. The parameter $\theta$ represents the share of marginal output that the government would, ideally, like to allocate to the rich. All other variables are as previously defined.

The first term on the right-hand side of (5) reflects the government's concern with inflation stabilization. Specifically, the government incurs losses when actual inflation deviates from the inflation target. The second term is intended to capture what many believe is a political reality for governments - namely, that voters reward governments for increases in output growth and penalize them for reductions in the growth rate. ${ }^{10}$ According to (1), increases in the output gap lead to increases in inflation, so that the government faces a tradeoff between its inflation and output objectives.

The third component in the government's loss function reflects the government's desire to allocate some portion of extra output to the achievement of objectives that are not directly related to price stabilization or output enhancement. These expenditures may be used as a direct means of income redistribution, or for the provision of

\footnotetext{
${ }^{9}$ The assumption that a fully independent central bank assigns a zero weight to transfer payments simplifies the algebra involved in solving the policy game without having any significant impact on the qualitative results.

${ }^{10}$ In existing studies of central bank independence, the output component in the government's loss function is more often represented as quadratic, rather than linear, because the models employed preclude any stabilization role for monetary policy when the output term in the loss function is linear. In this model, the additional quadratic income distribution term in the loss function allows monetary policy to play a role in output stabilization. As a practical matter, the linear output term allows me to obtain closed form solutions for the institutional parameters $\lambda^{c} b$ and $\delta$. Replacing the linear output term with a quadratic term yields first-order conditions that are quartic polynomials in at least one of the institutional parameters for which no closed form solutions are available.
} 
public goods such as schools and public transportation. ${ }^{11}$ Because such expenditures typically have, either directly or indirectly, some redistibutional element, I refer to these expenditures as transfer payments.

The ideal transfer is represented by $(b-\theta) y_{t}$, and the size of the actual transfer by $\tau_{t}^{r}$. Transfers, regardless of their precise nature, are not without cost. An increase in transfer payments $\tau_{t}^{r}$ must be financed either by raising tax revenues or by selling bonds to the central bank. Selling bonds to the central bank increases the money supply and also inflation. The government therefore faces a tradeoff between achieving its expenditure goals and moderating inflation.

Using taxes to finance transfer payments may also contribute to losses from the government's perspective. If the taxes are distortionary, then there may be economic costs in the form of dead-weight losses associated with tax increases. In this case the fourth term in (5) has the same interpretation as in Dixit and Lambertini (2003). ${ }^{12}$ Income tax increases would most surely be distortionary, but increases in the government's discretionary tax need not be if these take the form of non-distortionary lump-sum taxes. Even if increases in discretiory taxes are not distortionary, the government may still incur costs in the form of political penalties when discretionary taxes are increased. The reality is that voters typically do not like tax increases of any sort. The magnitude of $\lambda_{3}^{g}$ reflects the degree to which the government is concerned with the economic or political costs of using tax increases to finance its expenditures.

The extent to which the central bank is free to establish its own policy objectives depends on the degree of independence that the central bank enjoys. There are various ways in which the independence of central banks may be restricted. The gov-

\footnotetext{
${ }^{11}$ When this third component is viewed as a representation of the government's redistributional objectives, $\theta$ reflects the government's ideal degree of income inequality. In this case, $\theta$ is the proportion of any change in income that the government would, ideally, like to allocate to the wealthier members of society.

${ }^{12}$ Dixit and Lambertini (2003) provide microfoundations for an objective function that is similar to (5). Hughes Hallett and Weymark (2004) show that (5) encompasses Dixit and Lambertini's objective function.
} 
ernment may have at its disposal automatic credit facilities which force the central bank to finance government expenditures upon demand. There may be provisions that allow the government to borrow from the central bank at interest rates that are below market. These are examples of provisions that reduce the central bank's economic independence, that is, the central bank's ability to pursue policy objectives without having to take into account the objectives of the government. The government's ability to appoint central bankers with particular characteristics or to alter the statutes that govern the behavior of the central bank are further potential sources of influence. ${ }^{13}$ Legal provisions that prevent a government from populating the central bank with its own appointees are, in Grilli, Masciandaro, and Tabellini's (1991) terminology, a source of political independence. Other factors that contribute to political independence are, for example, the central bank's freedom to establish its inflation target independently and to implement monetary policy without first having to obtain government approval. Legal provisions that limit the government's ability to override the central bank and take control of monetary policy in times of conflict (i.e., legal provisions that grant the central bank instrument independence), also enhance political independence.

Rogoff's solution to Kydland and Prescott's time inconsistency problem requires a central bank that has full economic independence but is, at the same time, completely politically dependent. In this section I introduce a central bank objective function that allows for all possible degrees of economic independence, but maintains Rogoff's assumption of full political dependence. Formally, the central bank's objective function is specified as

$$
L_{t}^{c b}=\frac{1}{2}\left(\pi_{t}-\hat{\pi}\right)^{2}-\Omega y_{t}+\frac{\delta \lambda_{2}^{g}}{2}\left[(b-\theta) y_{t}-\tau_{t}^{r}\right]^{2}+\delta \lambda_{3}^{g} \tau_{t}
$$

where $\Omega=(1-\delta) \lambda^{c b}+\delta \lambda_{1}^{g}, 0 \leq \delta \leq 1$ reflects the central bank's degree of economic independence, $\lambda^{c b}$ is the weight that the central bank assigns to output growth relative

\footnotetext{
${ }^{13}$ Naturally, where there are binding statutes governing the behavior of the central bank, the ability to make partisan appointmentst will not be a source of influence.
} 
to inflation stabilization, and all other variables are as previously defined. ${ }^{14}$

A central bank's economic (or goal) independence is incomplete if the government has the ability to impose some of its own objectives on the central bank. The parameter $\delta$ measures the degree of economic independence that the government confers upon the central bank. The extreme values $\delta=0$ and $\delta=1$ represent perfect economic independence and complete dependence, respectively.

As specified, (6) includes two of the factors identified above as contributing to a central bank's political independence. When a central bank has full political independence, neither the central bank's inflation target, $\hat{\pi}$, nor it's relative weight on output, $\lambda^{c b}$, can be influenced by the government. For the purposes of this study, however, I assume that the government and the central bank share the same inflation target and that the government is able to exercise full control over $\lambda^{c b}$. The central bank is therefore assumed to be completely politically dependent. This assumption simplifies the algebraic derivations without affecting the qualitative results of the theoretical analysis that follows.

\section{The Policy Game}

The policy game that I consider is a two-stage non-cooperative game between the government and the central bank in which the structure of the model and the objective functions for both the government and the central bank are common knowledge. In the first stage, the government chooses the institutional parameters $\delta$ and $\lambda^{c b}$. The second stage is a simultaneous-move game in which the government and the monetary authority set their policy instruments, $\tau_{t}^{x}$ and $\tau_{t}^{r}$ for the government and $m_{t}$ for the monetary authority, given the values of $\delta$ and $\lambda^{c b}$ determined in the previous stage. The central bank is assumed to have full instrument independence and therefore controls the money supply $m_{t}$. The central bank's problem is to set $m_{t}$ so as to minimize its losses given the degrees of economic independence $(\delta)$ and conservatism

\footnotetext{
${ }^{14}$ Note that the absence of an income redistribution term in (6) is meant to reflect the fact that the mandates under which most central banks operate do not include income redistribution objectives.
} 
$\left(\lambda^{c b}\right)$ imposed upon it by the government. Private agents understand the game that the policy authorities are playing and form rational expectations about future prices in the second stage. Private agents are assumed to form these expectations at the beginning of the second stage, before the policy authorities implement their policies (but after the institutional parameters $\delta$ and $\lambda^{c b}$ have been determined). Formally, the two-stage policy game can then be described as follows:

\section{Stage 1}

The government solves the problem

$$
\begin{aligned}
\min _{\delta, \lambda^{c b}} \mathrm{E} L^{g}\left(\tau_{t}^{x}, m_{t}, \delta, \lambda^{c b}\right)=\mathrm{E}\{ & \frac{1}{2}\left[\pi_{t}\left(m_{t}\right)-\hat{\pi}\right]^{2}-\lambda_{1}^{g}\left[y_{t}\left(m_{t}\right)\right] \\
& \left.+\frac{\lambda_{2}^{g}}{2}\left[(b-\theta) y_{t}\left(m_{t}\right)-\tau_{t}^{r}\left(\tau_{t}^{x}, m_{t}\right)\right]^{2}\right\}
\end{aligned}
$$

where $L^{g}\left(\tau_{t}^{x}, m_{t}, \delta, \lambda^{c b}\right)$ is (5) evaluated at $\left(\tau_{t}^{x}, m_{t}, \delta, \lambda^{c b}\right)$, and $\mathrm{E}$ is the expectations operator.

\section{Stage 2}

(i) Private agents form rational expectations about future prices according to (A.1) before the shocks $u_{t}$ and $\epsilon_{t}$ are realized.

(ii) The shocks $u_{t}$ and $\epsilon_{t}$ are realized and observed by the government and by the central bank.

(iii) The government chooses $\tau_{t}^{x}$, taking $m_{t}$ as given, to minimize $L^{g}\left(\tau_{t}^{x}, m_{t}, \bar{\delta}, \bar{\lambda}^{c b}\right)$ where $\bar{\delta}$ and $\bar{\lambda}^{c b}$ indicates that these variables were determined in stage 1 .

(iv) The central bank chooses $m_{t}$, taking $\tau_{t}^{x}$ as given, to minimize

$$
\begin{aligned}
L^{c b}\left(\tau_{t}^{x}, m_{t}, \bar{\delta}, \bar{\lambda}^{c b}\right)=\frac{(1-\bar{\delta})}{2}\left[\pi_{t}\left(m_{t}\right)-\hat{\pi}\right]^{2}- & (1-\bar{\delta}) \bar{\lambda}^{c b}\left[y_{t}\left(m_{t}\right)\right] \\
& +\bar{\delta} L^{g}\left(\tau_{t}^{x}, m_{t}, \bar{\delta}, \bar{\lambda}^{c b}\right) .
\end{aligned}
$$

The policy game can be solved by first solving the second stage of the game for the optimal money supply and discretionary tax policies with $\delta$ and $\lambda^{c b}$ fixed, and 
then solving stage 1 by substituting the stage 2 results into (7) and minimizing with respect to $\delta$ and $\lambda^{c b}{ }^{15}$ The Nash equilibrium for the stage 2 game is

$$
\begin{array}{r}
m_{t}\left(\delta, \lambda^{c b}\right)=\hat{\pi}+\frac{\delta \lambda_{1}^{g}}{\alpha}+\frac{(1-\delta) \lambda^{c b}}{\alpha}+\frac{\delta \lambda_{3}^{g} \phi}{\alpha \beta}-\frac{\epsilon_{t}}{\beta}-\frac{u_{t}}{\alpha \beta} \\
\tau_{t}^{x}\left(\delta, \lambda^{c b}\right)=-\hat{\pi}-\frac{\delta \lambda_{1}^{g}}{\alpha}-\frac{(1-\delta) \lambda^{c b}}{\alpha}-\frac{\lambda_{3}^{g}}{\lambda_{2}^{g}}-\frac{\delta \lambda_{3}^{g} \phi}{\alpha \beta} \\
+\frac{[1-\beta(b-\theta-\tau b)] u_{t}}{\alpha \beta}+\frac{\epsilon_{t}}{\beta}
\end{array}
$$

where $\phi=1+\alpha \beta-\beta(b-\theta)$.

It is assumed that the government and the central bank observe the white noise disturbances, $u_{t}$ and $\epsilon_{t}$, in the second stage before policies are chosen, but after private expectations have been formed. Although private agents cannot observe $u_{t}$ and $\epsilon_{t}$ prior to forming expectations about future inflation rates, the characteristics of the institutions in place in the economy, represented by $\delta$ and $\lambda^{c b}$, are known to them. Under these conditions, it can be shown that (9) and (10) characterize a rational expectations equilibrium.

Using (1), (2), and (9), the solutions for $\pi_{t}$ and $y_{t}$ may be expressed as functions of the institutional variables $\delta$ and $\lambda^{c b}$

$$
\begin{gathered}
\pi_{t}\left(\delta, \lambda^{c b}\right)=\hat{\pi}+\frac{\delta \lambda_{1}^{g}}{\alpha}+\frac{(1-\delta) \lambda^{c b}}{\alpha}+\frac{\delta \lambda_{3}^{g} \phi}{\alpha \beta} \\
y_{t}\left(\delta, \lambda^{c b}\right)=\frac{-u_{t}}{\alpha}
\end{gathered}
$$

Substituting (3), (4), and (9)-(12) into (7), and then differentiating with respect $\lambda^{c b}$ and $\delta$ yields, respectively, the first-order conditions (13) and (14):

$$
(1-\delta)\left\{\beta \delta \lambda_{1}^{g}+\beta(1-\delta) \lambda^{c b}+\delta \lambda_{3}^{g} \phi-\alpha \beta \lambda_{3}^{9}\right\}=0
$$

\footnotetext{
${ }^{15}$ Details of the derivations of the main results presented in this section are provided in Appendix
} A. 


$$
\left\{\beta \lambda_{1}^{g}-\beta \lambda^{c b}+\lambda_{3}^{g} \phi\right\}\left\{\beta \delta \lambda_{1}^{g}+\beta(1-\delta) \lambda^{c b}+\delta \lambda_{3}^{g} \phi-\alpha \beta \lambda_{3}^{9}\right\}=0 .
$$

There are two solutions that satisfy both of the first-order conditions given above. By inspection, it is apparent that (13) and (14) are both satisfied when $\delta=1$ and $\lambda^{c b}=\lambda_{1}^{g}+\left(\lambda_{3}^{9} \phi / \beta\right)$. However, second order conditions show that this combination of $\delta$ and $\lambda^{c b}$ identifies a saddlepoint rather than a loss minimum. ${ }^{16}$ When $\delta \neq 1$ and $\lambda^{c b} \neq \lambda_{1}^{g}+\left(\lambda_{3}^{9} \phi / \beta\right)$, then (13) and (14) imply the following relationship between $\delta$ and $\lambda^{c b}$

$$
\delta=\frac{\alpha \beta \lambda_{3}^{g}-\beta \lambda^{c b}}{\lambda_{3}^{g} \phi+\beta \lambda_{1}^{g}-\beta \lambda^{c b}}
$$

Evaluating the government's expected loss when the combination of $\delta$ and $\lambda^{c b}$ is given by (15) yields

$$
\mathrm{E} L^{g}=-\lambda_{3}^{g}\left[\hat{\pi}+\frac{\lambda_{3}^{g}}{2}+\frac{\lambda_{3}^{g}}{2 \lambda_{2}^{g}}\right]
$$

Evidently, the government's expected loss is constant for all combinations of $\lambda^{c b}$ and $0 \leq \delta<1$ that satisfy (15). This observation together with the fact that the secondorder own-partials of $\mathrm{E} L^{g}$ are both strictly positive ensures that (16) is a global minimum.

\section{Optimal Conservatism and Economic Independence}

The solution to the policy game I have described has a number of interesting features. To begin with, the optimal institutional design always entails some degree of central bank independence. According to (15), there exists a continuum of combinations of $\delta$ and $\lambda^{c b}$ that minimize losses from the government's point of view. Consequently, partial independence can be just as successful as full independence as long as the degree of central bank conservatism is chosen appropriately. Differentiating (15) with respect to $\lambda^{c b}$ yields $\partial \delta / \partial \lambda^{c b}<0$, which shows that there is substitutability between central bank conservatism and independence. The impact of a decrease the central bank's economic independence can therefore be offset by appointing more

\footnotetext{
${ }^{16}$ When $\delta=1$ and $\lambda^{c b}=\lambda_{1}^{g}+\left(\lambda_{3}^{9} \phi / \beta\right)$ the Hessian matrix is negative semi-definite.
} 
conservative central bankers (that is, by reducing $\lambda^{c b}$ ). However, this does not imply that the optimal central bank must always be more conservative than the government with respect to its preference for output growth. ${ }^{17}$ It is straightforward to show that when the optimal combination of $\delta$ and $\lambda^{c b}$ is described by (15), $\lambda^{c b}<\lambda_{1}^{g}$ requires

$$
\frac{\lambda_{1}^{g}}{\lambda_{3}^{g}}>\frac{1}{\beta}\{\alpha \beta-\delta \phi\} .
$$

According to (17), the desirability of appointing a central banker who is more liberal than the government depends on (1) the government's preference for output expansion relative to its degree of tax aversion and (2) the net cost of monetary expansion, measured in terms of the inflation cost of output expansion $(\alpha \beta)$, as compared to its net benefit, measured as the marginal contribution to achieving the ideal transfer payment $(-\delta \phi) .{ }^{18}$ The greater is the priority assigned to output expansion relative to tax reduction, the greater is the likelihood that the government will prefer a more conservative central bank. If one accepts the conventional view that politically conservative governments tend to be more be more conservative with regard to the relative priority assigned to output growth over inflation control and also more tax averse than governments that are further to the left on the political spectrum, then (15) and (17) suggest that conservative governments should appoint more liberal central bankers, but grant these central bankers less independence, than a more liberal government should. Clearly, the inclusion of the tax penalty in the government's objective function is responsible for this interesting, and rather unconventional, insight. Setting $\lambda_{3}^{g}=0$ ensures that $\lambda^{c b}<\lambda_{1}^{g}$ for all $\lambda_{1}^{g}>0$.

Partial differentiation of (15) shows that for a given degree of central bank conservatism, the optimal degree of central bank independence is positively related to

\footnotetext{
${ }^{17}$ The notion that achieving the social optimum requires a liberal, rather than conservative central banker, has also been obtained in studies in which the models originally employed by Rogoff (1985) and Barro and Gordon (1983) have been extended to include inflation-averse trade unions. See, for example, Cukierman and Lippi (1999), and Guzzo and Velasco (1999). In these studies, appointing a liberal central banker eliminates inflation bias altogether.

${ }^{18}$ Note that $\partial\left[(b-\theta) y_{t}-\tau_{t}^{r}\right] / \partial m_{t}=-\phi /(1+\alpha \beta)$.
} 
both the priority assigned to output expansion $\left(\lambda_{1}^{g}\right)$ and the magnitude of the desired transfer payment $(b-\theta) y_{t} \cdot{ }^{19}$ The conventional interpretation of these results is that governments that have strong preferences for output expansion and income redistribution need a more independent central bank to prevent their expansionary tendencies from resulting in too high an inflation rate. This interpretation assumes that the weight assigned to output expansion by the government exceeds that of the central bank (i.e., $\lambda^{c b}<\lambda_{1}^{g}$ ). The same intuition is also valid for the current model when (17) is satisfied. However, when (17) is not satisfied, greater central bank independence is required to prevent the government's desire to avoid tax increases from resulting in a sub-optimally low transfer payment. In this case, greater central bank independence results in a higher, rather than lower, inflation rate.

Earlier studies of central bank independence have generally not included a tax penalty of any sort in the government's objective function. Consequently, the results of these studies indicate that inflation bias and government losses can simultaneously be minimized by delegating monetary policy to a conservative central banker. The results obtained here suggest that this may, in some cases, be too optimistic a view in that some governments may face a trade-off between dealing with problems of inflation bias and the achievement of other policy objectives. In particular, when the institutional design satisfies (15), the inflation rate is given by:

$$
\pi_{t}=\hat{\pi}+\lambda_{3}^{g}
$$

From (11), it is apparent that inflation bias can be eliminated completely by setting $\delta=\lambda^{c b}=0$, but this combination of independence and conservatism is only optimal if $\lambda_{3}^{g}=0$. Clearly, the combination of central bank independence and conservatism that minimizes inflation bias will not also minimize government losses when $\lambda_{3}^{g}$ is

\footnotetext{
${ }^{19}$ Partial differentiation of (15) with respect to $\delta$ also shows that the optimal degree of central bank independence is decreasing in the structural paramenters $\alpha$ and $\beta$. Eijffinger and Hoebericht's (1998) provide empirical evidence of the positive relationship between central bank independence $\delta$ and the impact of surprise inflation on output $1 / \alpha$.
} 
positive. $^{20}$

According to (15) there exists a continuum of combinations of $\delta$ and $\lambda^{c b}$ that minimize losses from the government's point of view. My model therefore cannot identify a unique solution to the government's institutional design problem. This last result was also obtained by Eijffinger and Hoeberichts (1998), which is the only other theoretical analysis that makes a formal distinction between central bank conservatism and central bank independence. On the positive side, the multiplicity of optimal combinations of $\delta$ and $\lambda^{c b}$ indicates that the optimal outcome can be achieved with a wide variety of institutional arrangements. The negative side of so much flexibility is that, for practical purposes, the choice among the alternative combinations will have to be made somehow, and this analysis offers no guidance as to how that choice should be made. From a purely technical point of view, the problem is one of overdetermination in that the model I have employed contains more instruments than objectives. Although my model is more complex than earlier models in this literature, it abstracts from many practical details in order to make the analysis tractable. First, the model does not reflect the political process by which the institutional design or re-design is accomplished. But the process by which decisions are reached may very well provide the mechanism by which one of the optimal combinations is chosen. Moreover, Cukierman (1994) has suggested that the degree of political instability and the extent to which there is consensus across political parties may be important in determining the preferred degree of central bank independence. Second, in reality decisions regarding institutional design are not made in a historical vacuum as they are here. Previous experience with inflation and the nature of institutions that economic agents are used to dealing with may make one of the possible optimal solutions more appealing than another.

Perhaps the most surprising implications of the policy game I have described are

\footnotetext{
${ }^{20}$ Debelle and Fischer (1994) obtain the same result. Having implicity set $\delta=0$ in their analysis, Debelle and Fischer find that setting $\lambda^{c b}=0$ mimizes inflation but does not minimize society's losses.
} 
that (1) complete economic independence (i.e., $\delta=0$ ) is not the unique loss minimizing solution and (2) there are circumstances in which it is optimal appoint a liberal central banker. Although there are a few studies, besides this one, that consider the benefits of appointing a liberal central banker, nearly all of the theoretical work and all of the empirical studies concerned with the relationship between central bank independence and inflation performance conclude that more central bank independence is better than less. ${ }^{21}$ The reason that (15) conflicts with the conclusions in previous studies is discussed in detail in the following section.

\section{Inflation and Central Bank Independence}

Theoretical studies of the time inconsistency problem as it pertains to the formulation of monetary policy typically do not allow the degree of economic independence and central bank conservatism to be chosen simultaneously. When these two institutional parameters are independently determined, the size of the inflation bias is found to be negatively related to the degree of economic independence conferred on the central bank. It is apparent from (11) that precisely the same conclusion is reached here if one changes $\delta$ while holding $\lambda^{c b}$ arbitrarily fixed. However, (18) shows that the inflation rate is invariant to changes in the degree independence as long as the combination of central bank independence and conservatism chosen satisfies (15).

The relationship between inflation and central bank independence has been estimated by Bade and Parkin (1982), Grilli, Masciandaro, and Tabellini (1991), Cukierman (1992), Alesina and Summers (1993), Eijffinger and Schaling (1993), and Franzese (1999), among many others. ${ }^{22}$ Many of these empirical studies find that central bank independence and the inflation rate are highly negatively correlated in high-income

\footnotetext{
${ }^{21}$ Lohmann (1992) is a notable an exception. Lohmann finds that when output disturbances are sufficiently large, it is to the government's benefit to restrict the central bank's independence. She therefore recommends that the central bank be granted full independence under "normal" conditions and only have this independence curtailed in times of economic exigency.

${ }^{22}$ Surveys of the contributions to this literature may be found in Eijffinger and de Haan (1996) and Berger, de Haan, and Eijffinger (2001).
} 
countries. The theoretical and empirical results have generally been interpreted as supporting the view that effective inflation control requires a high degree of central bank independence and that greater central bank independence is always better than less. Taken to its logical extreme, this line of reasoning implies that inflation is best controlled when central banks are granted full independence.

If it is true that changes in the degree of economic independence have no impact on the inflation rate when they are accompanied by an appropriate degree of central bank conservatism, how should one interpret the empirical finding that inflation is negatively correlated with the degree of economic independence? One interpretation that is consistent with the model presented here is that countries that grant their central banks less economic independence tend also to choose less efficient (evaluated on the basis of (15)) combinations of $\delta$ and $\lambda^{c b}$ and therefore experience higher inflation. Although this is certainly a possibility, it is not one that is particularly appealing.

An alternative explanation is that the systematic relationship between inflation and central bank independence that has been found in empirical studies arises from cross-country variations in economic structure and government objectives which jointly determine both the choice of institutional arrangements and inflation performance. Empirical studies that have focused on testing the validity of this explanation have not, as yet, delivered conclusive results. In part this may be because these studies have focused on different structural or behavioral factors. ${ }^{23}$ Studies have also differed in the composition of the countries included in the sample, the time period spanned, and the econometric techniques employed.

The view that differences in economic structure and preferences are the source of systematic differences in inflation performance is supported by the theoretical results obtained here. In particular, the results of this analysis concur with the findings of

\footnotetext{
${ }^{23}$ Posen (1995), for example, argues that the financial sector's opposition to inflation generates political pressure for governments to choose lower inflation rates. Campillo and Miron (1997), on the other hand, follow Romer (1993) and focus on the relationship between economic openness and inflation performance. Neither Posen nor Campillo and Miron find any evidence of a significant causal relationship between the degree of central bank independence and the average rate of inflation.
} 
empirical studies that have focused on the relationship between income inequality and inflation performance. Using the Gini coefficient as a measure of income inequality, Dolmas, Huffman, and Wynne (2000) found that there is a significant positive relationship between income inequality and average inflation. ${ }^{24}$ Furthermore, when inflation is regressed on income inequality and central bank independence, the coefficient for central bank independence is negative but not statistically significant. In the context of the model employed in this article, the government's commitment to redressing income inequality depends on the priority assigned to income redistribution and the government's willingness to levy taxes. Specifically, the expected transfer to the poor is given by

$$
\mathrm{E} \tau_{t}^{r}=-\frac{\lambda_{3}^{g}}{\lambda_{2}^{g}}
$$

According to (19), transfers to the poor are positively related to the priority assigned to income redistribution and negatively related to the government's desire to avoid tax increases. ${ }^{25}$ It follows that income inequality is positively related to $\lambda_{3}^{g}$. It is evident from (18) that inflation is increasing in $\lambda_{3}^{g}$ for all optimal combinations of central bank independence and conservatism. Differentiating (15) with respect to $\lambda_{3}^{g}$ yields

$$
\frac{\partial \delta}{\partial \lambda_{3}^{g}}=\frac{\alpha \beta^{2} \lambda_{1}^{g}+[1-\beta(b-\theta)] \beta \lambda^{c b}}{\left[\lambda_{3}^{g} \phi+\beta \lambda_{1}^{g}-\beta \lambda^{c b}\right]^{2}},
$$

which is clearly positive. It follows from (18) and (20) that although there is a negative correlation between central bank independence and inflation performance, this relationship is not causal. The model therefore provides theoretical support for the empirical results obtained by Dolmas, Huffman, and Wynne. ${ }^{26}$

\footnotetext{
${ }^{24}$ Beetsma and van der Ploeg (1996) use a different measure of inequality and find that there is a statistically significant positive relationship between inflation and income inequality in democratic countries, but not in non-democratic countries. Dolmas, Huffman, and Wynne find that the positive relationship between inflation and inequality holds for democracies and non-democracies.

${ }^{25}$ Note that although the expected transfer is negative, the realized transfer need not be, and will in fact be positive whevever $u_{t}<-\alpha \beta \lambda_{3}^{g} / \beta(b-\theta) \lambda_{2}^{g}$.

${ }^{26}$ In the model I have used, $\lambda_{3}^{g}$ is the only identifiable source of the correlation between inflation
} 
The policy game I have analyzed shows there is generally a negative correlation between central bank independence and inflation performance when governments design their monetary institutions optimally. This framework can also be used to show that when the degree of central bank conservatism is suboptimally low (i.e., when $\lambda^{c b}$ is too high), there is a positive correlation between central bank independence and inflation. According to (15), the optimal degree of central bank conservatism is

$$
\lambda^{c b}=\frac{\lambda_{3}^{g}[\alpha \beta-\delta \phi]-\delta \beta \lambda_{1}^{g}}{\beta(1-\delta)} .
$$

If a government appoints a central banker whose relative weight on output growth is $\tilde{\lambda}^{c b}=\lambda^{c b}+\eta$, then, from (11), the inflation rate is given by

$$
\pi_{t}(\delta)=\hat{\pi}+\lambda_{3}^{g}+\frac{(1-\delta) \eta}{\alpha}
$$

Differentiating (22) with respect to $\delta$ yields $\eta / \alpha$, which shows that central bank independence and inflation are positively related for $\eta>0$. Appointing a suboptimally liberal central banker therefore results in a positive (causal) relationship between central bank independence and inflation performance for all $0 \leq \delta \leq 1$.

In general, governments in middle and low income countries, where the tax base is small relative to that in high-income countries, rely more heavily on seigniorage revenue to finance government expenditures. It is plausible that the concern for preserving seigniorage revenue may lead governments in middle and low income countries to appoint central bankers who are not conservative enough, given their degree of independence. Equation (22) predicts that a systematic tendency among a group of performance and central bank independence. However, this is a model-specific feature and, in the case of the model I have employed, is a result of the assumption that Ricardian equivalence holds. If this assumption is relaxed, and government expenditures are allowed to have some positive effect on output, all of the government's behavioral parameters and all of the economy's structural parameters contribute to the negative correlation between inflation and central bank independence. The results obtained when Ricardian equivalence is relaxed are summarized in Appendix B. 
countries to appoint suboptimally liberal central bankers will be reflected in crosssectional data as a positive correlation between central bank independence and inflation. Thus, in making the relationship between central bank independence and inflation performance explicit, the model employed here offers a theoretical explanation for Cukierman, Webb, and Neyapti's (1992) empirical finding that central bank independence and average inflation rates are negatively correlated in high-income countries, but positively correlated in middle and low-income countries.

\section{Conclusion}

Cental bank conservatism and the degree of independence that the government confers on the central bank are two key components of the design of monetary institutions. In earlier studies of monetary policy delegation, only the degree of central bank conservatism has been endogenized; central bank independence has been treated as exogenous. In this article, I have used a two-stage non-cooperative game between the monetary authority and the government to endogenize both of these design features. The framework I employ makes a clear distinction between the objectives of a fully independent central bank and the government. In particular, a fully independent central bank is concerned only with inflation and output performance while the government, in addition to these two objectives, is also concerned with achieving an

expenditure target and minimizing tax increases. It turns out that the government's degree of tax aversion plays a critical role determining the nature of the optimal institutional design.

The results show that the optimal institutional design is not unique; there is a continuum of optimal combinations of central bank independence and conservatism. Furthermore, there is substitutability between central bank conservatism and independence, so a fully independent central bank represents only one of many possible optimizing designs. As long as the government places some positive weight on the avoidance of tax increases, some of these optimal combinations may be characterized by a liberal central bank. The results of my analysis show that a conservative cen- 
tral bank is more likely to be optimal when the marginal contribution of monetary expansion to the achievement of the government's expenditure target is large relative its impact on inflation. In this case a conservative central bank is needed to curtail the use of monetary policy as a means of financing government expenditures.

In addition to studying the relationship between central bank conservatism and independence, the game I have described can also be used to explore the relationship between independence and inflation performance. A large number of empirical studies have found a negative correlation between inflation and central bank independence in industrial countries. However, a causal relationship has not been convincingly established. The theoretical results obtained here show that inflation performance is invariant to changes in the optimal combination of central bank conservatism and independence. However, for any given degree of central bank conservatism, the optimal degree of central bank independence is negatively related to the government's inflation target. For optimizing countries, the negative correlation between central bank independence and inflation that has been found in cross-sectional empirical work may be a reflection of differences in inflation targets among the countries included in the sample. I also show that suboptimal combinations of central bank conservatism and independence result in a positive correlation between inflation and central bank independence. Specifically, when the central banker appointed by the government is too liberal, inflation and central bank independence are positively correlated.

\section{References}

Alesina, Alberto, "Macroeconomics and Politics," in Stanley Fischer (ed.) NBER Macroeconomics Annual, 1988, Cambridge, Mass: MIT Press, 11-55.

Alesina, Alberto, and Lawrence H. Summers, "Central Bank Independence and Macroeconomic Performance: Some Comparative Evidence," Journal of Money, Credit, and Banking 25, 1993, 151-62.

Alesina, Alberto, and Guido Tabellini, "Rules and Discretion with Noncoordinated Monetary and Fiscal Policies," Economic Inquiry XXV, 1987, 619-630. 
Bade, Robin, and Michael Parkin, "Central Bank Laws and Monetary Policy," unpublished manuscript, University of Western Ontario, 1982.

Beetsma, Roel M.W.J., and Frederick van der Ploeg, "Does Inequality Cause Inflation? The Political Economy of Inflation, Taxation, and Government Debt," Public Choice, 1996, 87, 143-62.

Beetsma, Roel W.J., and Hendrik Jensen, "Inflation Targets and Contracts with Uncertain Central Bank Preferences," Journal of Money, Credit, and Banking 30, 1998, 384-403.

Campillo, Marta and Jeffrey A. Miron, "Why Does Inflation Differ Across Countries?" in Christina D. Romer and David H. Romer (eds.) Reducing Inflation: Motivation and Strategy, 1997, University of Chicago Press, 335-357.

Cukierman, Alex, Central Bank Strategy, Credibility and Independence: Theory and Evidence, 1992, Cambridge, Mass: MIT Press.

Cukierman, Alex, Steven B. Webb, and Bilin Neyapti, "Measuring the Independence of Central Banks and its Effect on Policy Outcomes," World Bank Economic Review 6, 1992, 353-398.

Cukierman, Alex, and Francesco Lippi, "Central Bank Independence, Centralization of Wage Bargaining, Inflation and Unemployment - Theory and Some Evidence," European Economic Review 43, 1999, 1395-1434.

Debelle, Guy, "Central Bank Independence: A Free Lunch?" Massachesetts Institute of Technology, Mimeo, February 1994.

Debelle, Guy, and Stanley Fischer "How Independent Should a Central Bank Be?" In Jeffrey C. Fuhrer (ed.) Goals, Guidelines, and Constraints Facing Monetary Policymakers, Federal Reserve Bank of Boston Conference Series 38, 1994, 195221.

Dixit, Avinash and Luisa Lambertini, "Interactions of Commitment and Discretion in Monetary and Fiscal Issues," American Economic Review 93, 2003, 15221542.

Dolmas, Jim, Gregory E. Huffman, and Mark A. Wynne, "Inequality, Inflation, and 
Central Bank Independence," Canadian Journal of Economics 33, 2000, 271287.

Eijffinger, Sylvester C.W. and Jakob de Haan, The Political Economy of Central Bank Independence, Special Papers International Economics No. 19, 1996, Princeton University, Princeton, NJ.

Eijffinger, Sylvester C.W. and Marco Hoeberichts, "The Trade Off Between Central Bank Independence and Conservativeness," Oxford Economic Papers50, 1998, $397-411$.

Eijffinger, Sylvester C.W. and Eric Schaling, "Central Bank Independence in Twelve Industrialized Countries," Banca Nazionale del Lavoro Quarterly Review, March 1993, 49-89.

Franzese, Robert J. Jr., "Partially Independent Central Banks, Politically Responsive Governments' and Inflation," American Journal of Political Science 43, 1999, 681-706.

Grilli, Vittorio, Donato Masciandaro, and Guido Tabellini, "Political and Monetary Institutions and Public Financial policies in Industrial Countries," Economic Policy 13, 1991, 342-392.

Herrendorf, Berthold and Ben Lockwood, "Rogoff's 'Conservative' Central Banker Restored," Journal of Money, Credit, and Banking 29, 1997, 476-495.

Hughes Hallett, Andrew and Diana N. Weymark, "Independent Mondetary Policies and Social Equity," Economic Letters 85, 2004, 103-110.

Hughes Hallett, Andrew and Diana N. Weymark, "The Cost of Heterogeneity in a Monetary Union," Discussion Paper No. 3223, Center for Economic Policy Research, February 2002.

Jonsson, Gunnar, "Monetary Politics and Unemployment Persistence," Journal of Monetary Economics 39, 1997, 303-25

Kydland, Finn E. and Prescott, Edward C., "Rules Rather than Discretion: The Inconsistency of Optimal Plans," Journal of Political Economy 85, 1977, 47391. 
Lohmann, Susanne, "Optimal Commitment in Monetary Policy: Credibility versus Flexibility," American Economic Review 82, 1992, 273-286.

Lockwood, Ben, "State-Contingent Inflation Contracts and Unemployment Persistence," Journal of Money, Credit, and Banking 29, 1997, 286-299.

Lucas, Robert E., "Some International Evidence on Output-Inflation Trade-offs," American Economic Review 63, 1973, 326-334.

Lucas, Robert E., "Expectations and the Neutrality of Money," Journal of Economic Theory 4, April 1972, 103-124.

McCallum, Bennett T., Monetary Economics: Theory and Policy, 1989, New York, NY: Macmillan.

McCallum, Bennett T., "Two Fallacies Concerning Central Bank Independence," American Economic Review, Papers and Proceedings 85, 1995, 207-211.

Muscatelli, V. Anton, "Optimal Inflation Contracts and Inflation Targets Under Uncertainty: Why We Might Need Conservative Central Bankers," University of Glasgow Discussion paper No. 9802, January 1998.

Persson, Torsten and Guido Tabellini, "Designing Institutions for Monetary Stability," Carnegie Rochester Series on Public Policy 39, December 1993, 53-89.

Posen, Adam S., "Declarations are not Enough: Financial Sector Sources of Central Bank Independence," in Ben S. Bernanke and Julio Rotemberg (eds) NBER Macroeconomics Annual, 1995, Cambridge, Mass: MIT Press, 253-274.

Rogoff, Kenneth, "The Optimal Degree of Commitment to an Intermediate Monetary Target," Quarterly Journal of Economics 100, November 1985, 1169-89.

Romer, David, "Openness and Inflation: Theory and Evidence," Quarterly Journal of Economics 108, November 1993, 869-903.

Schaling, Eric, Marco Hoebrichts, and Sylvester Eijffinger, "Incentive Contracts for Central Bankers under Uncertainty: Walsh-Svensson Non-Equivalence Revisited," CentER for Economic Research Discussion Paper No. 9811, Tilburg University, February 1998.

Svensson, Lars E.O., 'Optimal Inflation Targets, 'Conservative' Central Banks, and 
Linear Inflation Contracts," American Economic Review 87, March 1997, 98114.

Guzzo, Vincenzo and Andres Velasco, "The Case for a Populist Central Banker," European Economic Review 43, 1999, 1317-1344.

Walsh, Carl E., "Optimal Contracts for Central Bankers," American Economic Review 85, 1995, 150-167.

Walsh, Carl E., Monetary Theory and Policy, 1998, Cambridge, Mass: MIT Press.

\section{Appendix A \\ Derivations of Key Results}

\section{A.1 Derivation of Equations (9) and (10)}

Substituting (2) into (1) and taking expectations results in

$$
\pi_{t}^{e}=m_{t}^{e}
$$

Using (1), (2), and (A.1) to solve for $\pi_{t}$ and $y_{t}$ yields the following semi-reduced form equations:

$$
\begin{aligned}
\pi_{t}\left(m_{t}\right) & =(1+\alpha \beta)^{-1}\left[\alpha \beta m_{t}+m_{t}^{e}+\alpha \epsilon_{t}+u_{t}\right] \\
y_{t}\left(m_{t}\right) & =(1+\alpha \beta)^{-1}\left[\beta m_{t}-\beta m_{t}^{e}+\epsilon_{t}-\beta u_{t}\right] .
\end{aligned}
$$

It is of course understood that $\pi_{t}$ and $y_{t}$ are functions not only of $m_{t}$, but also of $m_{t}^{e}$, $u_{t}$, and $\epsilon_{t}$. In order to make the notation less cumbersome, the period $t$ predetermined variable $m_{t}^{e}$ and the exogenous variables $u_{t}$ and $\epsilon_{t}$ have been suppresses on the righthand sides of (A.2) and (A.3).

Substituting (A.2) and (A.3) into (5) and then differentiating with respect to the government's policy instrument $\tau_{t}^{x}$ yields the government's stage 2 reaction function $\tau_{t}^{x}=-(1+\alpha \beta)^{-1}\left\{\phi m_{t}+\beta(b-\theta-\tau b) m_{t}^{e}+\beta(b-\theta-\tau b) u_{t}-(b-\theta-\tau b) \epsilon_{t}+\frac{\lambda_{3}^{g}}{\lambda_{2}^{g}}\right\}$. 
Similarly, the monetary authority's stage 2 reaction function can be obtained by substituting (A.2) and (A.3) into (6). This yields

$$
\begin{aligned}
m_{t}= & -\left[(\alpha \beta)^{2}+\delta \phi^{2} \lambda_{2}^{g}\right]^{-1}\left\{\delta \phi(1+\alpha \beta) \lambda_{2}^{g} \tau_{t}^{x}+\left[\alpha \beta+\beta(b-\theta-\tau b) \phi \delta \lambda_{2}^{g}\right] m_{t}^{e}\right. \\
& -\beta(1+\alpha \beta) \delta \lambda_{1}^{g}-\beta(1+\alpha \beta)(1-\delta) \lambda^{c b}-\alpha \beta(1+\alpha \beta) \hat{\pi}+\delta \beta b \tau(1+\alpha \beta) \lambda_{3}^{g} \\
& \left.+\left[\alpha \beta+\beta(b-\theta-\tau b) \phi \delta \lambda_{2}^{g}\right] u_{t}+\left[\alpha^{2} \beta-(b-\theta-\tau b) \phi \delta \lambda_{2}^{g}\right] \epsilon\right\} .
\end{aligned}
$$

Substituting (A.4) into (A.5), the monetary policy that private agents expect the central bank to implement at time $t$ is given by

$$
m_{t}^{e}=\hat{\pi}+\frac{\delta \lambda_{1}^{g}}{\alpha}+\frac{(1-\delta) \lambda^{c b}}{\alpha}+\frac{\delta \lambda_{3}^{g}}{\alpha \beta}[1+\alpha \beta-\beta(b-\theta)]-\frac{u_{t}}{\alpha \beta}-\frac{\epsilon_{t}}{\beta} .
$$

Using (A.6) in (A.4) and (A.5) and then solving simultaneously for $m_{t}$ and $\tau_{t}^{x}$ yields the Nash equilibrium for the stage 2 policy game given by (9) and (10) in Section 4 of the main text.

\section{A.2 Derivation of Equations (13) and (14)}

Substituting (10)-(12) into (7), the government's stage 1 minimization problem can be expressed as

$$
\begin{aligned}
\min _{\delta, \lambda^{c b}} \mathrm{E} L^{g}\left(\delta, \lambda^{c b}\right)= & \frac{1}{2}\left\{\frac{\delta \lambda_{1}^{g}}{\alpha}+\frac{(1-\delta) \lambda^{c b}}{\alpha}+\frac{\delta \lambda_{3}^{g}}{\alpha \beta}[1+\alpha \beta-\beta(b-\theta)]\right\}^{2}+\frac{\left(\lambda_{3}^{g}\right)^{2}}{2 \lambda_{2}^{g}} \\
& -\lambda_{3}^{g}\left\{\hat{\pi}+\frac{\delta \lambda_{1}^{g}}{\alpha}+\frac{(1-\delta) \lambda^{c b}}{\alpha}+\frac{\delta \lambda_{3}^{g}}{\alpha \beta}[1+\alpha \beta-\beta(b-\theta)]+\frac{\lambda_{3}^{g}}{\lambda_{2}^{g}}\right\} .
\end{aligned}
$$

Partial differentiation of (A.7) with respect to $\lambda^{c b}$ results in

$$
\frac{\partial \mathrm{E} L^{g}\left(\delta, \lambda^{c b}\right)}{\partial \delta}=(1-\delta)\left\{\frac{\delta \lambda_{1}^{g}}{\alpha}+\frac{(1-\delta) \lambda^{c b}}{\alpha}+\frac{\delta \phi \lambda_{3}^{g}}{\alpha \beta}\right\}-\lambda_{3}^{g}(1-\delta)=0 .
$$

Differentiating (A.7) with respect to $\delta$ yields

$$
\begin{aligned}
\frac{\partial \mathrm{E} L^{g}\left(\delta, \lambda^{c b}\right)}{\partial \delta}=\left\{\frac{\delta \lambda_{1}^{g}}{\alpha}+\frac{(1-\delta) \lambda^{c b}}{\alpha}+\frac{\delta \phi \lambda_{3}^{g}}{\alpha \beta}\right\}\left\{\frac{\lambda_{1}^{g}}{\alpha}-\frac{\lambda^{c b}}{\alpha}+\frac{\phi \lambda_{3}^{g}}{\alpha \beta}\right\} & \\
& -\lambda_{3}^{g}\left\{\frac{\lambda_{1}^{g}}{\alpha}-\frac{\lambda^{c b}}{\alpha}+\frac{\phi \lambda_{3}^{g}}{\alpha \beta}\right\}=0
\end{aligned}
$$


Simple rearrangement of (A.8) and (A.9) yields (13) and (14), respectively.

\section{Appendix B}

\section{Productive Government Expenditures}

In the main text Ricardian equivalence was assumed to hold so government expenditures could not have any impact on output growth. One consequence of imposing Ricardian equivalence is that except for the case in which it is optimal to grant the central bank no independence at all, the inflation rate associated with an optimally designed central bank depends only on the chosen inflation target and the government's degree of tax aversion $\left(\lambda_{3}^{g}\right)$. In this appendix I show that relaxing the Ricardian equivalence assumption results in optimal inflation rates that depend on all of the government's behavioral parameters and all of the economy's structural parameters

In the context of the model I employ, relaxing Ricardian equivalence implies that output in (2) depends on both real money balances and government expenditures. The output equation therefore becomes:

$$
y_{t}=\beta\left(m_{t}-\pi_{t}\right)+\gamma g_{t}+\epsilon_{t}
$$

Having introduced government expenditures into the model, it is now also necessary to amend the governments budget constraint (3) which becomes

$$
g_{t}+\tau_{t}^{r}=m_{t}+\tau_{t}
$$

For simplicity, I fix $\tau_{t}^{x}=\bar{\tau}^{x}$ in (4) and set $\lambda_{3}^{g}=0$ in the government's objective function (5).

Using this model variation to solve the policy game, has no effect on the equilibrium level of output. However, inflation is now given by

$$
\pi_{t}\left(\delta, \lambda^{c b}\right)=\hat{\pi}+\frac{(1-\delta) \beta \Gamma \lambda^{c b}}{\alpha[\beta \Gamma+\delta \gamma \Lambda]}+\frac{\delta[\beta \Gamma+\gamma \Lambda] \lambda_{1}^{g}}{\alpha[\beta \Gamma+\delta \gamma \Lambda]}
$$

where $\Gamma=1+\alpha \beta+b(1-\tau) \gamma-\gamma \theta$ and $\Lambda=1+\alpha \beta-b(1-\tau) \beta+\beta \theta$. Substituting (A.12) and (12) into (5) and then differentiating with respect to $\lambda^{c b}$ and $\delta$ results in 
first-conditions that identify two potential optimal solutions to the policy game. The first solution is one in which the central bank is fully dependent while the second requires combinations of independence and conservatism that satisfy

$$
\delta=\frac{\beta \Gamma^{2} \lambda^{c b} \lambda_{2}^{g}+(\alpha \gamma)^{2} \beta\left(\lambda^{c b}-\lambda_{1}^{g}\right)}{\beta \Gamma^{2} \lambda^{c b} \lambda_{2}^{g}+(\alpha \gamma)^{2} \beta\left(\lambda^{c b}-\lambda_{1}^{g}\right)-\Gamma[\beta \Gamma+\gamma \Lambda] \lambda_{1}^{g} \lambda_{2}^{g}} .
$$

It is straightforward to show that (A.13) is the loss minimizing solution. Substituting (A.13) into (A.12) yields

$$
\pi_{t}=\hat{\pi}+\frac{\alpha \gamma^{2} \lambda_{1}^{g}}{\left[(\alpha \gamma)^{2}+\Gamma^{2} \lambda_{2}^{g}\right]}
$$

From (A.13) and (A.14) it is evident that both the optimal degree of central bank independence and the inflation rate in an economy with an optimally configured central bank may be jointly determined by both the behavioral characteristics of the government and the structural characteristics of the economy. It can also be shown that this joint dependence results the sorts of negative correlations between central bank independence and inflation that have been identified in empirical studies. Further discussion of this issue may be found in Weymark (2001). 